\title{
The United States Polar Rock Repository: A geological resource for the Earth science community
}

\author{
Anne M. Grunow, ${ }^{1}$ David H. Elliot, ${ }^{2}$ and Julie E. Codispoti ${ }^{1}$ \\ ${ }^{1}$ U.S. Polar Rock Repository, Byrd Polar Research Center, Ohio State University, 108 Scott Hall, 1090 Carmack Road, Columbus, OH 43210, USA \\ (grunow.1@osu.edu, codispoti.8@osu.edu) \\ ${ }^{2}$ School of Earth Sciences, Ohio State University, 125 South Oval Mall, Columbus, OH 43210, USA (elliot.1@osu.edu)
}

\begin{abstract}
The United States Polar Rock Repository (USPRR) is a U. S. national facility designed for the permanent curatorial preservation of rock samples, along with associated materials such as field notes, annotated air photos and maps, raw analytic data, paleomagnetic cores, ground rock and mineral residues, thin sections, and microfossil mounts, microslides and residues from Polar areas. This facility was established by the Office of Polar Programs at the U. S. National Science Foundation (NSF) to minimize redundant sample collecting, and also because the extreme cold and hazardous field conditions make fieldwork costly and difficult. The repository provides, along with an on-line database of sample information, an essential resource for proposal preparation, pilot studies and other sample based research that should make fieldwork more efficient and effective. This latter aspect should reduce the environmental impact of conducting research in sensitive Polar Regions. The USPRR also provides samples for educational outreach. Rock samples may be borrowed for research or educational purposes as well as for museum exhibits.

Citation: Grunow, A.M., D.H. Elliot, and J.E. Codispoti (2007), The United States Polar Rock Repository: A Geological Resource for the Earth Science Community, in Antarctica: A Keystone in a Changing World - Online Proceedings of the $10^{\text {th }}$ ISAES, edited by A.K. Cooper and C.R. Raymond et al., USGS Open-File Report 2007-1047, Short Research Paper 068, 3 p.; doi:10.3133/of2007-1047.srp068
\end{abstract}

\section{Introduction}

Conducting geological research in the remote and hostile environments of Antarctica and the Arctic is difficult and expensive. Because of the extensive ice cover (up to $98 \%$ in Antarctica), samples from the few terrestrial outcrops are precious. The sediment core drilling community (marine and lacustrine) has long had an organized structure for saving and curating cores (the Ocean Drilling Program, Lamont-Doherty Earth Observatory, LacCore-Limnological Research Center, the Antarctic Research Facility [ARF], among others) but this is not true of terrestrial sample collections. Even though public monies have funded field work, rock samples have traditionally remained with the original collector and have sometimes been discarded, misplaced and/or left uncurated, hence lost to the scientific community. The National Science Foundation and the US polar earth science community recognized the need for, and value of, preserving rock samples from polar regions and hence created the United States Polar Rock Repository (USPRR) (Figure 1) (Askin and Grunow, 2003). The US Polar Rock Repository opened on the

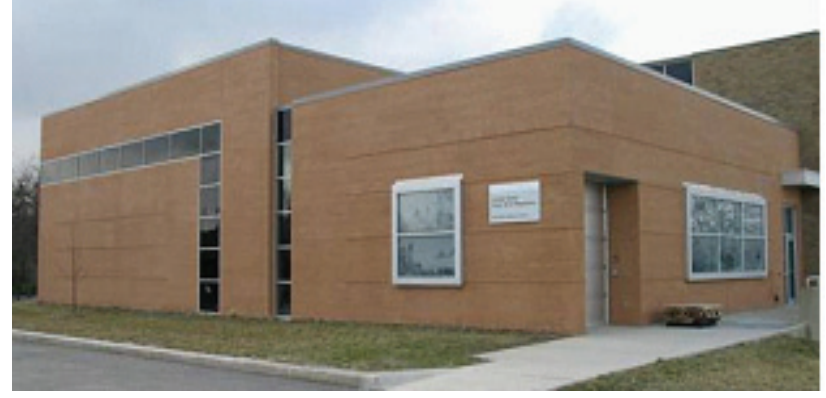

Figure 1. The U. S. Polar Rock Repository campus of the Ohio State University in October 2003. The creation of the USPRR fulfills an obligation under the Antarctic Treaty (section III.1.c) which states that "Scientific observations and results from Antarctica shall be exchanged and made freely available." In addition, data exchange is stipulated as part of the International Polar Year (IPY) such that all samples collected during IPY must be archived and accompanied by a metadata description.

\section{Facility}

The USPRR is located adjacent to the Byrd Polar Research Center and is approximately 4300 sq- $\mathrm{ft}$. The climate-controlled building contains 12' high storage shelving racks that can be converted into movable shelving when the first storage units are full. Approximately 70,000 specimens can be stored on the current shelving and double that amount with additional racks. Samples can be examined in a layout area equipped with tables, weighing scales, Ethernet connections, etc. Visitors may use a work area/conference room outfitted with a Leica petrographic microscope and attached digital video camera, a light table, computer, printer, scanner, polar books and maps. A rock preparation room is on site to cut specimens. The USPRR will provide the following services as requested by scientists and educators: 1) rock sawing of samples; 2) coring of samples ( $25 \mathrm{~mm}$ diameter); 3) bulk magnetic susceptibility measurements; 4) magnetic intensity measurements using a JR5A magnetometer; 5) thin section photomicrographs; 6) scans of field maps and sketches. Sub-sets of samples are available for analysis by qualified investigators from around the world. The USPRR is unusual among rock repositories in providing 
immediate on-line access to terrestrial rock sample metadata and in accepting sample loan requests. Other polar geological databases and repositories exist (e.g. British Antarctic Survey, Alfred Wegener Institute, the Italian Antarctic Research program, among others) but access to the geological collections is limited. Visitors also have access to other laboratories and equipment at the Byrd Polar Research Center and in the OSU Department of Geological Sciences with prior arrangement.

\section{Research support provided by the USPRR collection}

The USPRR maintains a database about the rock samples, as well as a magnetic property database assembled from published and unpublished paleomagnetic data (Plate 1). The USPRR uses commercial software called EMu (by KE Software) as the in-house and online database for the repository (http://www-bprc.mps.ohio-state.edu/emuwebusprr). The online sample database is one of the most comprehensive geological databases available to researchers, educators and museums worldwide. The database provides a fast way to search the collection using multiple terms. The database includes basic geological information about the samples but also includes other information which may be of value to researchers (Plate 2). Shared metadata fields of the rock sample and magnetic property data include: collector, object details, locality, measurements, age and bibliography.

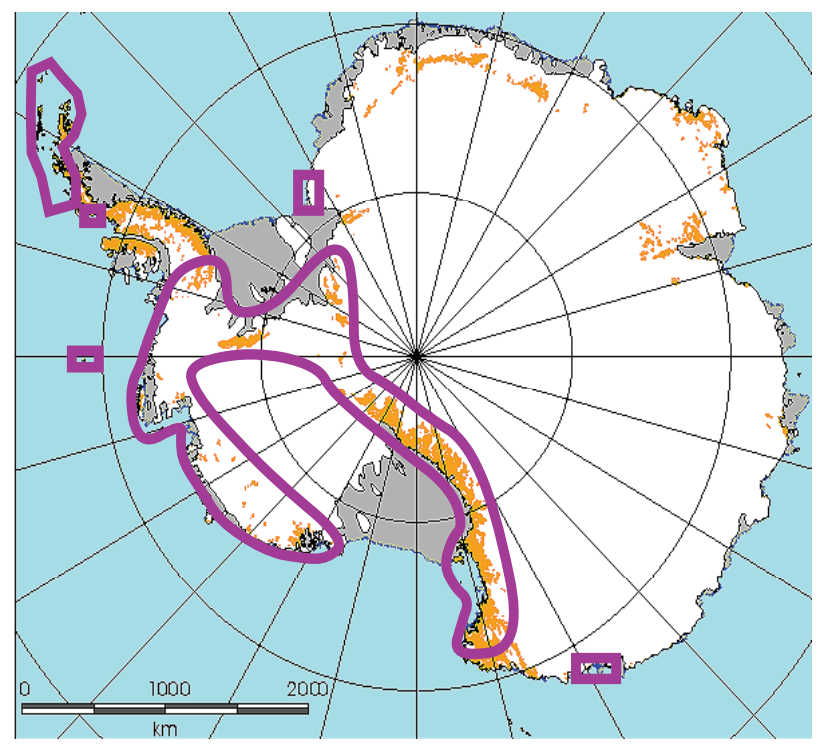

Figure 2. Locations of cataloged samples at the USPRR.

\section{Rock sample collections at the USPRR}

As of May 2007, the USPRR collection included more than 12,000 samples from many parts of Antarctica (Figure 2). The USPRR sample collection includes terrestrial rock samples, unconsolidated material, dredges and terrestrial cores. In addition to the samples, associated materials such as field notes, annotated air photos and maps, raw analytic data, paleomagnetic cores, ground rock and mineral residues, thin sections, and microfossil mounts, microslides and residues are cataloged and entered into the online database.

Many of the samples were collected prior to official place names, and therefore original field sites have been correlated with current place names (using the Gazetteer of the Antarctic). The rock samples were collected primarily from West Antarctica, the Transantarctic Mountains and some from cratonic East Antarctica. All samples are relabeled with a USPRR number, weighed, photographed and measured for magnetic susceptibility (if the sample is large enough). Apart from this information, we include many other aspects of metadata associated with the sample including geographical location, sample description, collector, age, images as well as the following:

- Location features: Unusual features about the sample area are included, such as algal ponds, glacial grooves, ancient shorelines, moraines, cavernous weathering, etc. This information may be of use to investigators studying topics concerning glacial geology, paleoclimate, paleobiology etc.

- Structural data: Field structural information is valuable to investigators planning field work. It is also of value to structural geologists trying to assess the tectonic and kinematic history of an area.

- Logistics: The USPRR incorporates information about the primary and secondary logistics used by past collectors. In addition, when available, field camp locations are noted. This information facilitates remote camp location planning.

- Multimedia: All samples are photographed (front and back). Field location maps, stratigraphic sections and outcrop photos are included.

- Observations: Information is included about minerals observed, analyses conducted, fossils observed, location in the section and distance from igneous intrusions. Also noted are: staining, lichen, surface encrustations, wind blasting, etc.

\section{Rock physical property data}

The US Polar Rock Repository (http://bprc.mps.ohiostate.edu/rr/samples/) maintains compilations of Antarctic rock magnetic and other physical properties (Grunow, 2003) and provides the data online at the USPRR website. Thousands of paleomagnetic samples, representing more than 1700 oriented sites have been collected in Antarctica from Precambrian through late Cenozoic rocks, and various rock magnetic physical property data are listed in the database, including susceptibility and natural remnant intensity. The database has provided geological information for interpretations based on the Antarctic Digital Magnetic Anomaly Project 
(ADMAP) database, and has been used in modeling the sub-ice basement rocks of Antarctica (Vogel et al., 2003; Vogel et al., 2007; von Frese et al., 2007). It is also of use to paleoclimatologists investigating the provenance of Antarctic marine sediments.

\section{Scientific and community outreach \\ Tours and talks}

As part of local community outreach, the USPRR curator and staff conduct tours and give lectures about Antarctic field work to more than 1300 adults and children each year visiting the repository. There is an area in the repository where children can try on Antarctic clothing and climb into a Scott tent and imagine what it's like to be a scientist in Antarctica. Talks and geology demonstrations showing rock samples are given at schools in Ohio.

\section{Website}

For the public community, there are website links: Virtual Tour of the Repository, Meet the Curator, Kids Space and Frequently Asked Questions. There is also an educational website containing information and activities for K-12 (Plate 3). At the elementary school level, there is a teachers' guide and hand's-on activities for students learning about Antarctica and an option for teachers to borrow an "Antarctic Rock Box" containing representative rocks from the three main rock types, books and activities about geology and Antarctica. The activities have been designed and reviewed by educators and scientists to use as an educational supplement to the Earth Science course of study. The learning activities have been designed around the Academic Content Standards: k-12 Science manual published by the Ohio Department of Education and the Center for Curriculum and Assessment to ensure that the activities and topics focused on the content standards that are mandated by the state, and thus an integral part of instruction, curriculum, and assessment.

There is also a Virtual Web Expedition with many activities for high school students. At the high school level, students learn about how to plan a field season, learn about safety techniques, how to make a remote field camp, identify what equipment is needed, learn about the different transportation choices, weather issues, understanding GPS, etc.

\section{Undergraduate education}

Undergraduate students from the School of Earth Sciences work in and actively use the repository. The students learn about the geologic history of Antarctica, curation methods, how to use spreadsheet software and acquire software imaging skills.

\section{Scientific links}

The USPRR is a partner with SESAR (System for Earth Sample Registration). SESAR is a centralized registry that provides and administers unique identifiers for Geoscience samples - the International Geo Sample Number IGSN (link: http://www.geosamples.org). The IGSN is a serial number to be used when sample-based data is reported in publications and databases so that data can be referenced unambiguously to the correct sample.

\section{Public awareness}

The USPRR is advertised biweekly in EOS published by AGU, monthly in GSA Today and online in GeoMart. The USPRR is also listed as links on the following websites: NSF-OPP Antarctic Geology and Geophysics, SESAR, the US Antarctic Data Coordination Center.

\section{Summary}

The USPRR is a valuable resource to the scientific community because it advances knowledge about polar geology in regions that are often not well known because of logistical and ice-cover constraints. By encouraging researchers to access samples in the USPRR collection first, the facility lessens the environmental impact of research in Polar regions. The online database facilitates field work planning, improving the science, efficiency, and safety of field operations. The USPRR provides a way for teachers and children to learn about Antarctica via the website (http://www-bprc.mps.ohiostate.edu/emuwebusprr), borrowing a "Rock Box" and by visiting the Byrd Polar Research Center.

Acknowledgements. We thank John Goodge, Sam Mukasa (reviewers) and Carol Finn (editor) for providing helpful reviews of this manuscript. The USPRR is supported by the U.S. National Science Foundation, Office of Polar Programs under grant NSF-OPP 0440695.

\section{References}

Askin, R.A. and A. M. Grunow (2003), The United States Polar Rock Repository and Antarctic Geologic Database, ISAES meeting, Sept. 613, Potsdam, Germany.

Grunow, A.M. (2003), The Antarctic Rock Magnetic Database: an overview, ISAES meeting, Sept. 613, Potsdam, Germany.

Grunow, Anne M. (2003), Magnetic property information and the new Antarctic rock magnetic database; an overview; Sridhar Anandakrishnan, editor; Goodge, John W., editor; Kurt S. Panter, editor; Christine S. Siddoway, editor; Terry J. Wilson, editor Open File Report U. S. Geological Survey OF 030065. Reston, VA: U.S. Geological Survey.

Vogel, S.W., S. Tulaczyk, A. M. Grunow (2003), Provenance of West Antartic subglacial sediment, SEAP workshop, March, Boulder, CO.

Vogel, S.W., S. Tulaczyk, S. Carter, P. Renne, B. Turrin, A. Grunow (2007), Geologic constraints on the existence, distribution of West Antarctic subglacial volcanism, Geophysical Research Letters, in press.

von Frese, R.R.B., S.V. Golynsky, H.R. Kim, L. GayaPiqué, E. Thébault, M. Chiappini, A. Grunow, and the ADMAP Working Group (2007, in press), The next generation Antarctic digital magnetic anomaly map, 10th International Symposium on Antarctic Research. 